\title{
Lugol chromoendoscopy: might it be useful to improve detection of early dysplastic or neoplastic lesions of the anal canal in high-risk patients?
}

Lugol is a vital dye that reacts with the glycogen of malpighian nonkeratinized epithelia. Normal mucosa is stained brown by Lugol, whereas pathologic mucosa remains unstained [1]. In smokers and those with alcohol addiction, Lugol increases the sensitivity of the endoscopic detection of dysplasia and squamous cell carcinoma of the esophagus [2]. We wondered whether Lugol might also improve detection of such lesions in the anal canal of high-risk patients. Indeed, most of the anal canal is covered with malpighian nonkeratinized epithelium, separated from the glandular rectal mucosa by a transitional cell epithelium. First, we wanted to prove the feasibility of this procedure for the anal canal, and to test it in patients with anal carcinoma, before and after treatment. Thus, after perfect cleansing, we sprayed $2 \%$ Lugol by retroflexion in the rectum with a gastroscope, in eight female patients without iodine allergy. The patients had squamous cell carcinoma of the anal canal, and had either not yet been treated ( $n=5$ examinations, in five patients), or had been previously treated by radiochemotherapy and did not show detected recurrence by clinical examination, conventional endoscopy or endosonography ( $n=9$ examinations, in five patients). Overall, two patients underwent the Lugol staining both before and after radiochemotherapy. Results were assessed after 2 minutes.

All malpighian areas that were endoscopically normal were intensely and wholly stained by Lugol, whereas the carcinomas that had not yet been treated and glandular mucosa remained unstained ( $\bullet$ Fig. 1 and 2 ). Tolerance of the procedure was good.

In conclusion, we proved the feasibility of Lugol chromoendoscopy of the anal canal, a procedure not previously described, to our knowledge. So, we intend to test it further, with the aim of improving the detection of dysplasia and early carcinoma in high-risk diseases of the anal canal, namely previously treated squamous cell carcinoma, condylomas [3] and chronic anal localizations of Crohn's disease [4,5].

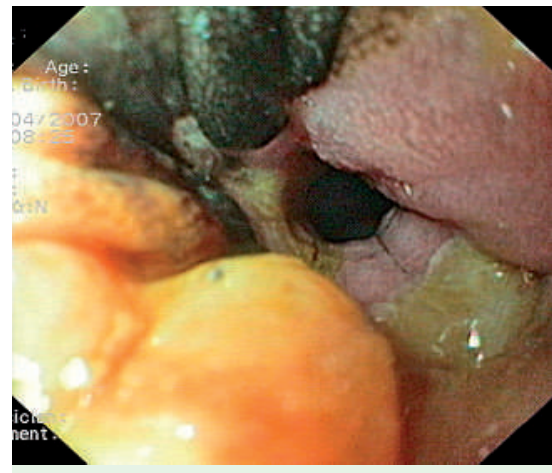

Fig. 1 Direct vision: lack of brown coloration of a squamous cell carcinoma of the anal cana after Lugol staining.

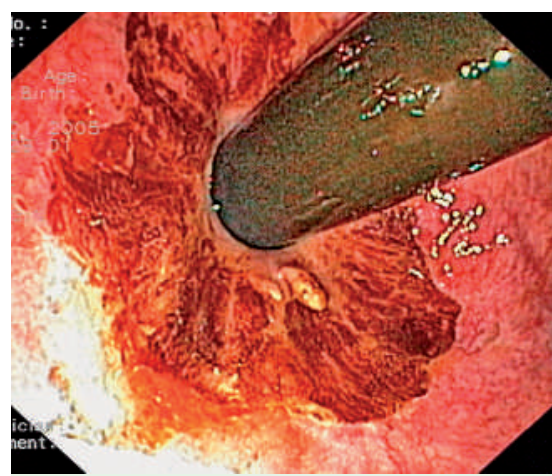

Fig. 2 Retroflexion vision: homogeneous brown coloration of the upper part of the anal canal after Lugol staining in a patient previously treated for a squamous cell carcinoma of the anal canal without macroscopic recurrence.

Endoscopy_UCTN_Code_CCL_1AD_2AB

\section{Antonietti, S. Lecleire,}

E. Ben Soussan, B. Paillot, F. Di Fiore,

E. Lerebours, P. Ducrotté

Department of Gastroenterology, Rouen University, Charles Nicolle Hospital, Rouen, France

\section{References}

1 Misumi A, Harada K, Murakami A. Role of lugol dye endoscopy in the diagnosis of early esophageal cancer. Endoscopy 1990; 22: $12-16$

2 Dubuc J, Legoux JL, Winnock $M$ et al. Endoscopic screening for esophageal squamous cell carcinoma in high-risk patients: a prospective study conducted in 62 french endoscopy centers. Endoscopy 2006; 38: 690-695

3 Sobhani I, Vuagnat A, Walker F et al. Prevalence of high-grade dysplasia and cancer in the anal canal in human papillomavirus-infected individuals. Gastroenterology 2001; 120: 1046 - 1048

4 Preston DM, Fowler EF, Lennard-Jones JE, Hawley PR. Carcinoma of the anus in Crohn's disease. Br J Surg 1983; 70: 346 347

5 Ky A, Sohn N, Weinstein MA, Korelitz BI. Carcinoma arising in anorectal fistulas of Crohn's disease. Dis Colon Rectum 1998; 41: $992-996$

Bibliography

DOI $10.1055 / \mathrm{s}-2007-966863$

Endoscopy 2008; 40: E47

(c) Georg Thieme Verlag KG Stuttgart · New York . ISSN 0013-726X

Corresponding author

M. Antonietti, MD

Department of Gastroenterology

Rouen University

Hospital Charles Nicolle

1 rue de Germont

76031 Rouen Cedex

France

Fax: + 33-2-35151623

michel.antonietti@chu-rouen.fr 